Research Article

\title{
Ground Response and Mining-Induced Stress in Longwall Panel of a Kilometer-Deep Coal Mine
}

\author{
Zhaohui Wang $\mathbb{D}^{1},{ }^{1}$ Shengli Yang $\mathbb{D}^{2},{ }^{2}$ Guoliang Xu $\left(\mathbb{D},{ }^{1}\right.$ and Zhijie Wen ${ }^{3}{ }^{3}$ \\ ${ }^{1}$ School of Energy and Mining Engineering, China University of Mining and Technology, Beijing 100083, China \\ ${ }^{2}$ Coal Industry Engineering Research Center of Top Coal Caving Mining, China University of Mining and Technology, \\ Beijing 100083, China \\ ${ }^{3}$ Key Laboratory of Mining Disaster Prevention and Control, Shandong University of Science and Technology, \\ Qingdao 266590, China
}

Correspondence should be addressed to Zhijie Wen; 1301591557@qq.com

Received 29 December 2020; Accepted 16 March 2021; Published 27 March 2021

Academic Editor: Traian Mazilu

Copyright $(2021$ Zhaohui Wang et al. This is an open access article distributed under the Creative Commons Attribution License, which permits unrestricted use, distribution, and reproduction in any medium, provided the original work is properly cited.

In order to improve ground control of the longwall mining, ground response and mining-induced stress in the longwall panel of a kilometer-deep coal mine are investigated in this study. Field measurements on abutment stress, roof displacement, and fracture development indicate that the region influenced by the longwall mining reaches $150 \mathrm{~m}$ ahead of the longwall face. Failure scope of the coal seam, where mining-induced fractures are well developed, ranges from 10 to $13 \mathrm{~m}$ inward the face line. Vertical stress concentration coefficient reaches 2.2. Based on the field measurements, a numerical model is moreover developed and utilized to examine the response of the principal stress to the longwall mining. The concentration coefficient, peak point location, and influence scope of the principal stress gradually become stable with an increase in face advancement. Regarding the major principal stress, the concentration coefficient and influence scope are 2.4 and $152 \mathrm{~m}$, respectively, and the peak point locates $13 \mathrm{~m}$ inward the face line, which are consistent with the field measurements. With respect to the minor principal stress, the referred coefficient and scope are 1.5 and $172 \mathrm{~m}$, respectively, and its peak point location is $21 \mathrm{~m}$ ahead of the face line. The major principal stress in the coal seam rotates from vertical to horizontal direction in the vertical plane parallel with face advance direction. The maximum rotation angle reaches $20^{\circ}$. The minor principal stress first rotates into the referred vertical plane and then it rotates from horizontal to vertical direction at the same speed with the major principal stress in the same plane. Rotation angle of the principal stress in roof strata is greatly enlarged, the rotation trace of which is influenced by the longwall mining and vertical distance above the seam. Based on the relation between rotation trace of the principal stress and face advance direction, the influence of stress rotation on the stability of roof structure is discussed.

\section{Introduction}

In the past decade, the depth of underground coal mining increased by 10 to $20 \mathrm{~m}$ per year in China [1,2]. As a result, the mining-induced stress becomes increasingly large and the stability of the surrounding rock is dramatically deteriorated [3]. Such changes in mining conditions cause continuous growth in the frequency of mining accidents, such as face fall, roof fall, support failure, or even dynamic disasters [4-6]. It is widely accepted that serious ground responses are closely related to the stress environment, which is important to the design of the ground control system in the longwall mining. Thus, the distribution of mining-induced stress and associated ground responses have been extensively studied with many methods in deep coal mines.

Field measurement serves as the most fundamental method of examining ground response and mining-induced stress. Xie et al. investigated mining-induced stress distribution in the longwall panel of a kilometer-deep coal mine with borehole stress monitoring method [7]. The results indicated that the influence scope of front abutment stress reaches about $100 \mathrm{~m}$, and peak point of the abutment stress locates about 10 to $20 \mathrm{~m}$ inward the face line. Chang et al. 
studied the influence of the adjacent gob on the distribution of the abutment stress [8]. Peak stress in the unmined coal seam showed an increasing trend with decrease in the distance from the gob edge. Song et al. proposed an electromagnetic radiation-based method in assessing the mining-induced stress [9]. The intensity of the electromagnetic signal was positively related to the stress magnitude. With vibrating wire stress meters, mining-induced stress distribution in coal pillars was monitored in sixteen underground coal mines. It was revealed that the influence region and peak value of the vertical stress are positively related to the cover depth and hardness of the overburden [10]. By installing stress sensors in the inclined borehole, Guo et al. found that the influence scope of the longwall mining reached $300 \mathrm{~m}$ [11]. The vertical stress experienced a peak point at a distance of $28 \mathrm{~m}$ ahead of the face line while horizontal stress maintained a continuous decreasing trend. With the specifically designed stress cells, the stress path undergone by the surrounding rock at Winston Lake Mine in Canada has been monitored. During the mining process, the principal stresses in different directions experienced a concentration phenomenon consistently. Based on the stress path, two types of failure modes in the surrounding rock were recognized at the mine site [12]. Recently, the compact conical ended borehole monitoring system has been extensively used in long-term investigation of full stress tensor changes in cooperation with the seismicity monitoring system. A positive relation between the stress level and seismic signal frequency has been achieved $[13,14]$. According to such a relation, it was found that the mininginduced stress showed an increasing trend with the face length [15]. With respect to the relationship between the stress magnitude and cover depth, the mining-induced stress increased linearly and the ratio between horizontal and vertical stresses decreased nonlinearly from a large value of 3.5 to 1.0 with an increase in the cover depth $[16,17]$.

Based on the field measurements, a series of empirical models have been established to predict the distribution of mining-induced stress. By simplifying the coal into infinite, elastic, isotropic, and homogeneous material, Salamon first proposed an empirical equation for stress distribution at the edge of the longwall panel [18]. However, this empirical equation could not match subsequent field measurements, which were illustrated in a nomograph by Whittaker and Singh [19]. The nomograph proved to be accurate for the stress distribution around the longwall panel, but it was difficult to be mathematically expressed. Wilson separated the unmined coal seam ahead of the longwall face into two zones, namely, the failure and intact zones [20]. Accordingly, the distribution curve for vertical stress was also divided into two pieces, where the cover depth, mining height, and material properties of the surrounding rock were taken into account. Recently, Xue et al. discussed the mining-induced discontinuous stress drop observed in deep coal mines [21]. A damage index was defined for the failure zone based on fracture development in the unmined coal seam. The peak stress in the failure zone decreased with the damage index, causing onset of the stress drop at the boundary between the failure and intact zones ahead of the longwall face.
The field measurement and theoretical equation are applicable in analyzing the stress distribution along specific lines. However, quantitative evaluation of mining-induced stress in three dimensions is of more interest in dealing with surrounding rock stability. Numerical simulation provides an effective way for analyzing the mining-induced stress more precisely. Shabanimashcool and $\mathrm{Li}$ proposed a methodology for simulating progressive underground mining with continuum-based software, where the movement of overburden strata was considered $[22,23]$. Thus, the mining-induced stress could be realistically reproduced. Ju et al. adopted a continuum-based discrete element method to simulate the evolution of mining-induced stress in a longwall panel [24]. This method was capable of characterizing the heterogeneity of coal measure rocks, bedding separation, dislocation, as well as caving of the multilayered rock strata. Basarir et al. simulated the stress distribution around the gate during longwall top-coal caving [25]. It turned out that the maximum magnitude of the abutment stress increased to about 3 times the initial value. Besides, the orientation of the principal stress changed frequently. By including a discontinuous interface in the numerical model, the dynamic disaster resulting from mining-induced stress and tectonic stress was investigated, and the mining arrangement at the near-fault region was optimized [26]. Numerical modeling of 3D stress rotation ahead of an advancing tunnel face indicates that the rotation angle of the principal stress was so large that its influence on the stability of the surrounding rock should be underlined [27, 28]. The rotation phenomenon led to a more complex propagation path of mining-induced fractures. Such stress rotation also occurred in the top coal during longwall top-coal caving. The rotation trace depended heavily on the panel layout, which influenced top-coal cavability to a large extent [29-31]. In deep coal mines, stress-relief measures were commonly carried out to control problems related to mining-induced stress. Kang et al. greatly decreased the front abutment stress by using the hydraulic fracturing method [32].

The ground response and mining-induced stress of longwall mining has been extensively investigated. However, the study associated with longwall mining in kilometer deep coal mine is limited. In such a longwall panel, ground response and stress distribution become more complex. In order to improve the surrounding rock control, ground response and mining-induced stress in a longwall panel with cover depth of more than $1000 \mathrm{~m}$ is thoroughly analyzed in the present study. The emphasis is placed on the rotation of the principal stress and potential influences provided by the stress rotation.

\section{Engineering Background}

2.1. Geological and Mining Conditions. The Kouzidong coal mine is located in Huainan city of Anhui province, China. The high reach single pass longwall mining method is utilized to extract a thick coal seam. The target panel of this study is 121304, as shown in Figure 1(a). On its right side is a gob remaining after the extraction of panel 121303. The other side is unmined coal seam. Several faults exist within 


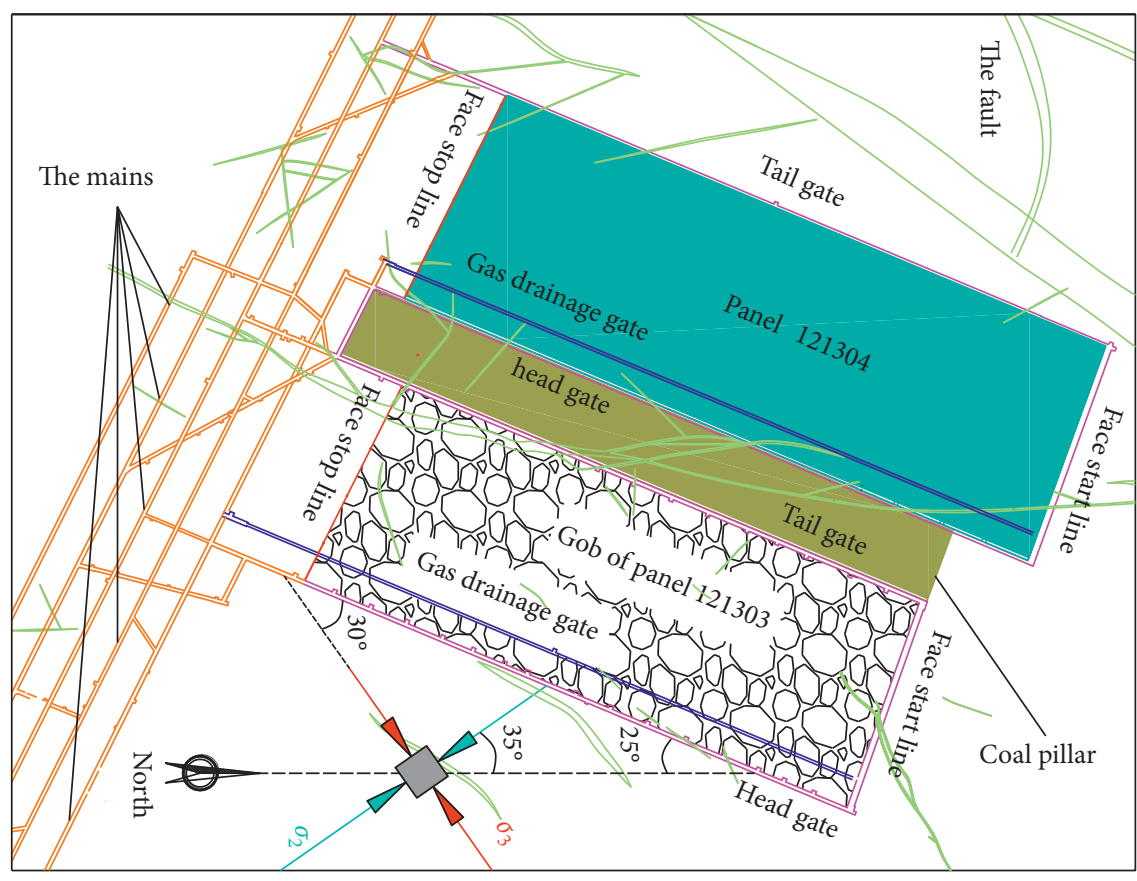

(a)

\begin{tabular}{|c|c|c|c|}
\hline Column & Thickness & Rock & Roof \\
\hline & $3.10 \mathrm{~m}$ & Mudstone & $\begin{array}{l}\begin{array}{l}\text { Roof } \\
\text { strata }\end{array} \\
\end{array}$ \\
\hline & $4.10 \mathrm{~m}$ & Sandstone & \multirow{3}{*}{$\begin{array}{l}\text { Main } \\
\text { roof }\end{array}$} \\
\hline & $5.56 \mathrm{~m}$ & Siltstone & \\
\hline & $2.20 \mathrm{~m}$ & Sandstone & \\
\hline & $2.70 \mathrm{~m}$ & Mudstone & \multirow{3}{*}{$\begin{array}{c}\text { Immediate } \\
\text { roof }\end{array}$} \\
\hline & $3.25 \mathrm{~m}$ & Siltstone & \\
\hline & $4.40 \mathrm{~m}$ & Mudstone & \\
\hline & $5.18 \mathrm{~m}$ & Coal & Coal seam \\
\hline & $5.50 \mathrm{~m}$ & Mudstone & $\begin{array}{l}\text { Floor } \\
\text { strata }\end{array}$ \\
\hline & & & \\
\hline
\end{tabular}

(b)

Figure 1: Mining conditions. (a) Plane view of the panel. (b) Geological column.

the region between panel 121303 and panel 121304. Thus, a large coal pillar, $100 \mathrm{~m}$ wide, is left between the referred two panels to protect the tail gate of the target panel. The longwall face, $350 \mathrm{~m}$ in length, is installed at the face start line and advances toward the mains until the face stop line is reached. The longwall face advances in the direction of $\mathrm{S} 30^{\circ} \mathrm{W}$. The extracted coal seam is $5.6 \mathrm{~m}$ thick with average cover depth of $1080 \mathrm{~m}$. It is a flat seam with dip angle smaller than $8^{\circ}$. According to rock core logging, a simple geological column is obtained and illustrated in Figure 1(b). In panel 121304 , the immediate roof is composed of mudstone and siltstone, which are thin and soft. The main roof is composed of siltstone and sandstone, which are thick and hard. The immediate roof caves timely behind the longwall face, so that the gob left behind is partially backfilled. The main roof is so hard that it fails in the form of bending rupture. Periodic rupture of the main roof leads to roof weighting in the longwall face.

2.2. Initial Ground Stress and Rock Properties. Initial ground stress has been in situ measured at the Kouzidong coal mine. The results reveal that the major principal stress is approximately in the vertical direction, whose magnitude is equal to $24 \mathrm{MPa}$. The angle between the major principal and vertical directions is smaller than $12^{\circ}$. The intermediate principal stress, $21.2 \mathrm{MPa}$ in magnitude, is parallel with $\mathrm{N} 30^{\circ} \mathrm{W}-\mathrm{S} 30^{\circ} \mathrm{E}$ direction in the horizontal plane. The minor principal stress, with the magnitude of $15 \mathrm{MPa}$, is perpendicular to the immediate principal stress in the horizontal plane. There is an angle equal to $30^{\circ}$ existing between the minor principal and face advance directions (see Figure 1(a)).
According to Figure 1(b), the overburden strata of panel 121304 are mainly composed of mudstone, siltstone and sandstone. Accordingly, both cylindrical and disk samples of the coal and roof rocks are prepared for compression and Brazilian tests. Rock properties are deduced from the experimental results and listed in Table 1, where $E$ and $v$ are elastic modulus and Poisson ratio, respectively.

2.3. Problems in the Surrounding Rock Control. Under the geological and mining conditions of the Kouzidong mine, surrounding rocks in both longwall face and gate way experience serious damage after influenced by the longwall mining. A series of rock instabilities observed at the mine site are presented in Figure 2. A large coal block falls to the floor from the longwall face in Figure 2(a). Large-scale face fall causes subsequent roof fall and even instability of the hydraulic support (Figure 2(b)). Both roof fall and face fall drastically threaten the safety of the mining environment in the longwall face. In addition, the gateway presents large deformation characteristics. Initial cross section of the tail gate of panel 121304 reaches $12.6 \mathrm{~m}^{2}$. After being influenced by the longwall mining, the cross section decreases to about $2.1 \mathrm{~m}^{2}$ (Figure 2(c)). Material transport and panel ventilation are dramatically influenced by the large deformation. In order to prevent such bad influences, both rib expanding and floor dinting are executed in the tail gate of panel 121304 (Figures 2(d)-2(e)). In fact, surrounding rock instabilities presented in Figure 2 are attributed to the stress redistribution resulting from the longwall mining. Thus, mininginduced stress should be investigated for optimizing the ground control. 
TABLE 1: Rock properties from the experimental test.

\begin{tabular}{lcccccc}
\hline Rock type & $E(\mathrm{GPa})$ & $v$ & Cohesion $(\mathrm{MPa})$ & Friction $\left(^{\circ}\right)$ & Tensile strength $(\mathrm{MPa})$ & Uniaxial compressive strength $(\mathrm{MPa})$ \\
\hline Coal & 3.6 & 0.20 & 5.2 & 33 & 1.8 & 20 \\
Mudstone & 18.6 & 0.25 & 8 & 35 & 3.2 & 31 \\
Siltstone & 20.6 & 0.25 & 12 & 40 & 6.4 & 52 \\
Sandstone & 32.0 & 0.16 & 18 & 42 & 11.2 & 80 \\
\hline
\end{tabular}

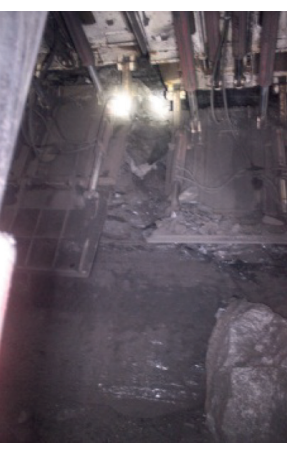

(a)

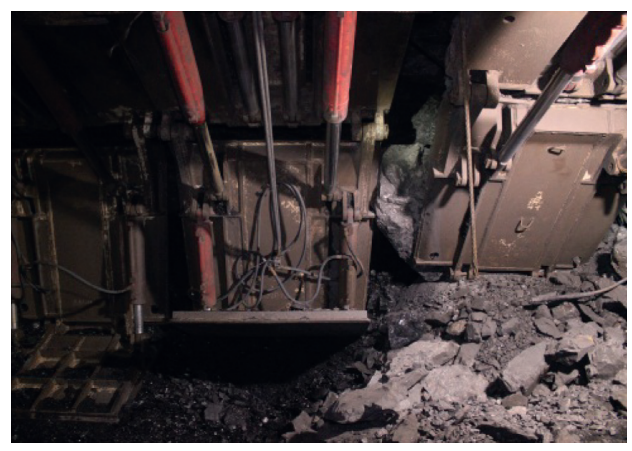

(b)

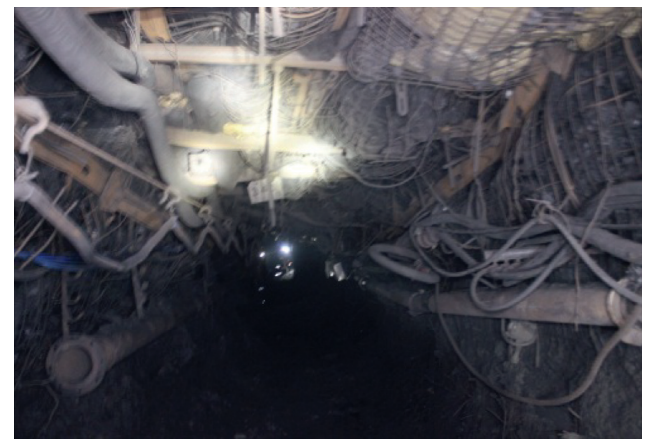

(c)

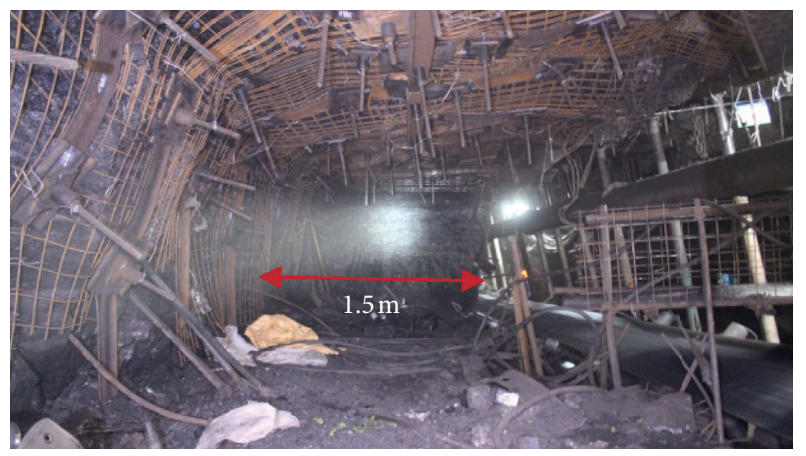

(d)

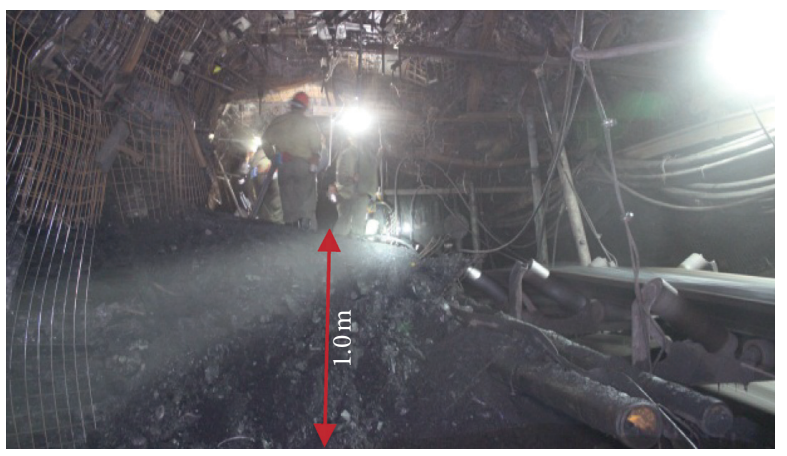

(e)

Figure 2: Surrounding rock instabilities. (a) Face fall. (b) Roof fall. (c) Large deformation of the gate. (d) Rib expanding. (e) Floor dinting.

\section{Field Investigations on the Ground Response}

3.1. Monitoring Method. In order to achieve ground response characteristics, a series of field measurements have been carried out at the Kouzidong coal mine. Three monitoring stations are installed in the head gate. The location of the first station is $150 \mathrm{~m}$ ahead of the longwall face. The interval between different monitoring stations is $20 \mathrm{~m}$. At the station, one horizontal and two vertical boreholes are drilled in the side rib and roof strata of the gate, which are $15 \mathrm{~m}$ in depth. The borehole stress sensor, which is widely used to investigate vertical stress distribution in underground coal mine, is buried at the bottom of the horizontal borehole. An oil pump, connected to the stress sensor with flexible pipeline, is left outside of the borehole (Figure 3(a)). Hydraulic oil is injected into the stress sensor through the oil pump to make the sensor contact tightly with the borehole wall. Note the largest oil pressure that the stress sensor can bear commonly ranges from 20 to $25 \mathrm{MPa}$. In the longwall mining, the concentration coefficient of the vertical stress at its peak point commonly falls between 2 and 4 . Thus, the initial value of the stress sensor should not be larger than a quarter of the largest value. The load-bearing capacity of the borehole stress sensor used in this study is $20 \mathrm{MPa}$. The initial pressure of the injected oil is accordingly set to be $5 \mathrm{MPa}$, which is much smaller than the initial ground stress $(24 \mathrm{MPa})$. One vertical borehole is utilized to install the displacement sensor (Figure 3(b)), which in fact is the twopoint extensometer. The extensometer is composed of two anchors. One anchor (A) is fixed at the bottom of the borehole, which locates in the main roof. The other anchor (B) is fixed at the location $6 \mathrm{~m}$ inside the borehole, which locates in the immediate roof. Borehole camera detection is carried out in another vertical borehole. The data from the stress sensor and displacement sensor are recorded with the same data collector.

3.2. Vertical Stress Distribution. Vertical stress distribution obtained from the borehole stress sensor is presented in Figure 4 . The vertical stress at three monitoring stations shows a similar evolution process. Initial magnitude is equal to the initial pressure of the hydraulic oil injected into the stress sensor, which ranges from 5 to $6 \mathrm{MPa}$. At the location $150 \mathrm{~m}$ ahead of the face line, the vertical stress shows an increasing trend. That means the coal in the vicinity of the 


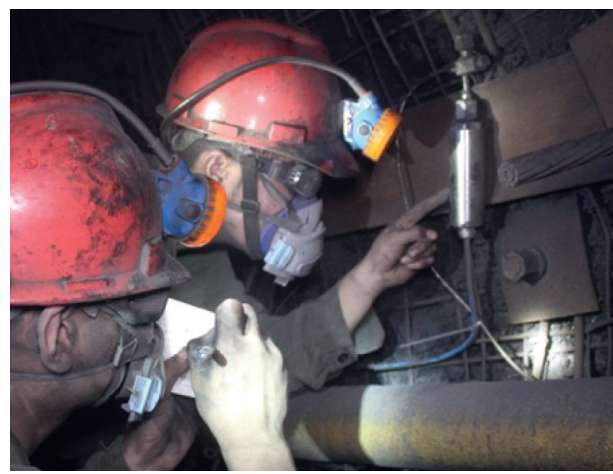

(a)

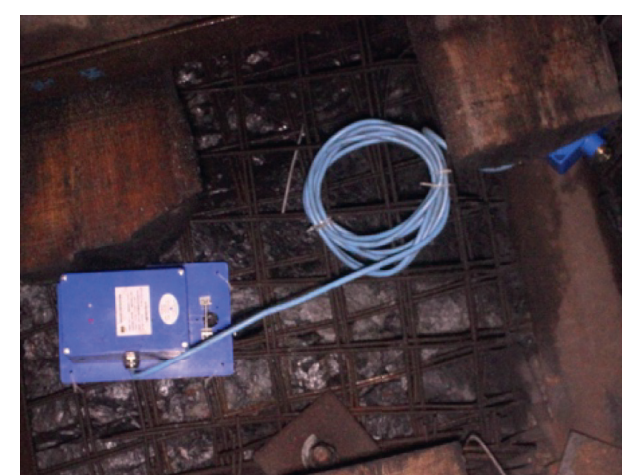

(b)

Figure 3: Installation of the monitoring apparatus. (a) Stress sensor. (b) Displacement sensor.

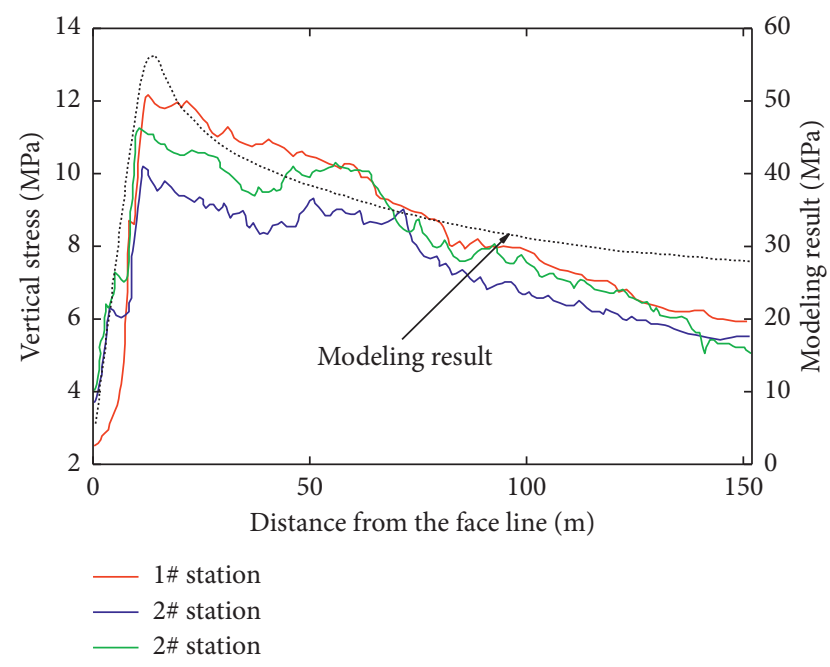

FIgURE 4: Vertical stress distribution.

monitoring station is influenced by mining operations at the longwall face. Shrink of the borehole wall causes an increase in the oil pressure. During the growing process, the vertical stress experiences local fluctuation due to frequent crushing of the borehole wall. Such an increasing stage ends at the location 11 to $13 \mathrm{~m}$ inward the face line, where a peak point is reached by the vertical stress. The peak point arrives at 10 to $12 \mathrm{MPa}$, and the stress concentration coefficient is approximately equal to 2.2 . After the peak point, the coal fails. Development of mining-induced fractures leads to continuous loss of the load-bearing capacity in the coal. Thus, the vertical stress starts to decrease. At the face line, vertical stress decreases to about 2.5 to $3.5 \mathrm{MPa}$, which is consistent with residual strength of the coal in the uniaxial compression test. According to the vertical stress distribution, the region of the coal seam influenced by mining operations expands to $150 \mathrm{~m}$ ahead of the face line. Due to the large cover depth, the width of fracturing area reaches 11 to $13 \mathrm{~m}$, much larger than that in the longwall panel with a small cover depth $[33,34]$. Note, due to the small installation pressure ( 5 to $6 \mathrm{MPa}$ ), the vertical stress obtained from the borehole stress sensor is much lower than the real value. However, the evolution trend is reliable and extensively utilized to evaluate the distribution of mining-induced stress. The vertical stress is commonly named as the abutment stress. Its evolution trend is consistent with the abutment stress distribution in situ observed by Chang [8].

3.3. Roof Displacement. Evolution of the roof displacement is shown in Figure 5. Note anchor A, in the main roof, locates $15 \mathrm{~m}$ above the coal seam, and anchor $\mathrm{B}$, in the immediate roof, is $6 \mathrm{~m}$ above the coal seam. According to Figure 5, vertical displacement of the immediate roof is larger than that of the main roof. The immediate roof starts to subside at about $150 \mathrm{~m}$ ahead of the face line. The initial subsidence position of the main roof locates $10 \mathrm{~m}$ behind that of the immediate roof. After that, an increasing rate of the vertical displacement in the immediate roof is larger than that in the main roof. In addition, an increasing rate of the vertical displacement in the immediate roof keeps relatively stable in the monitoring process. However, an increasing rate of the vertical displacement in the main roof changes continuously. That is attributed to relatively low sensitivity of the main roof to the longwall mining. At $1 \#$ and $3 \#$ monitoring stations, the main roof subsides abruptly at the location $5 \mathrm{~m}$ ahead of the face line. Such a quick increase in vertical displacement is attributed to bending rupture of the main roof. The abrupt increase in the vertical displacement is not experienced by the anchor at station 2 , which means that the main roof does not fracture when the longwall face approaches to this station. At the face line, vertical displacements in the immediate roof are $110 \mathrm{~mm}, 116 \mathrm{~mm}$, and $130 \mathrm{~mm}$ at $1 \#, 2 \#$, and $3 \#$ monitoring stations, respectively. In contrast, at the referred stations, vertical displacements underwent by the anchors installed in the main roof are $62 \mathrm{~mm}, 70 \mathrm{~mm}$, and $75 \mathrm{~mm}$. That means the bedding separations between immediate and main roof strata reach $48 \mathrm{~mm}, 46 \mathrm{~mm}$, and $55 \mathrm{~mm}$, respectively. Such an evolution in the vertical displacement is consistent with that observed by Xie [2].

3.4. Fracture Development in Roof Strata. Fracture development in roof strata is presented in Figure 6. When the monitoring station is $50 \mathrm{~m}$ ahead of the face line, the coal 


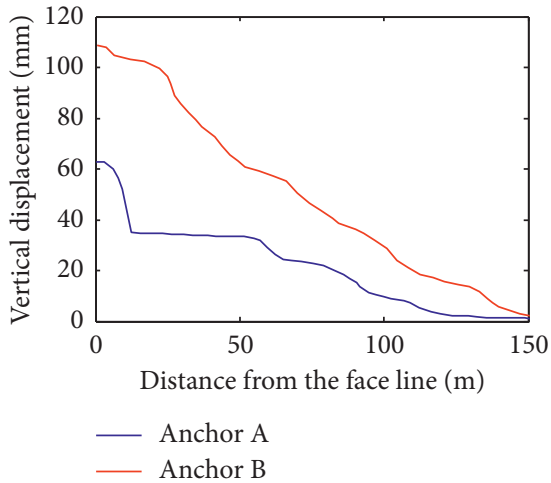

(a)

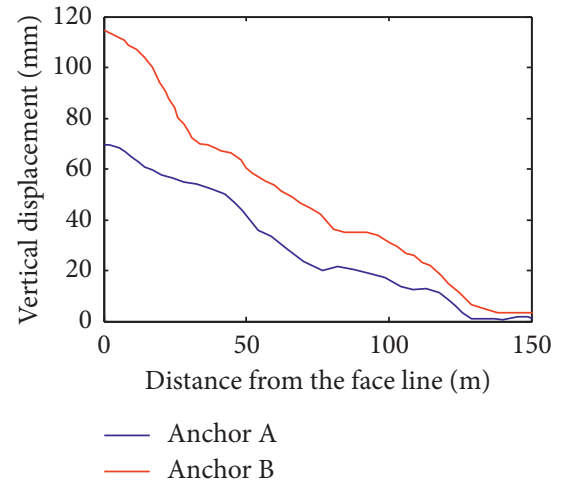

(b)

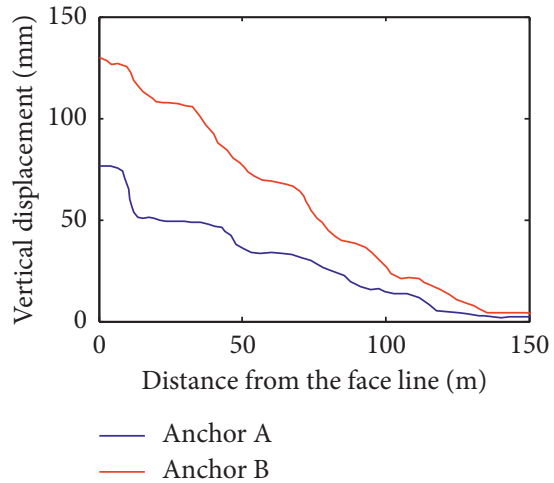

(c)

Figure 5: Vertical displacement of roof strata. (a) 1\# station. (b) 2\# station. (c) 3\# station.

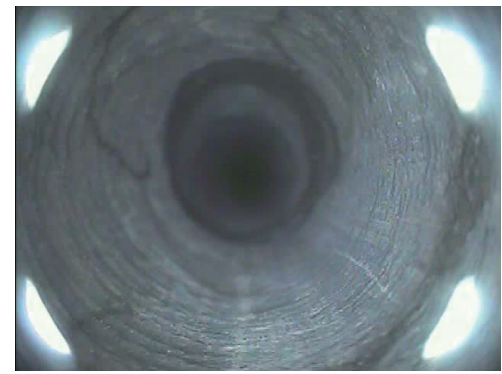

Depth $=12 \mathrm{~m}$

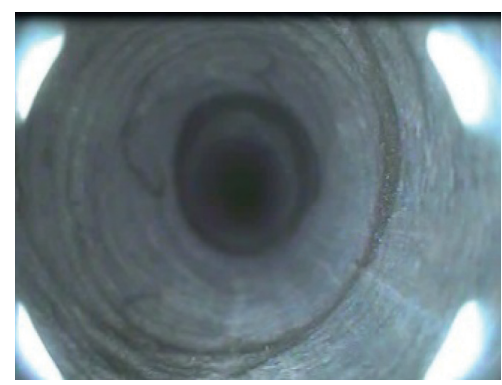

Depth $=12 \mathrm{~m}$

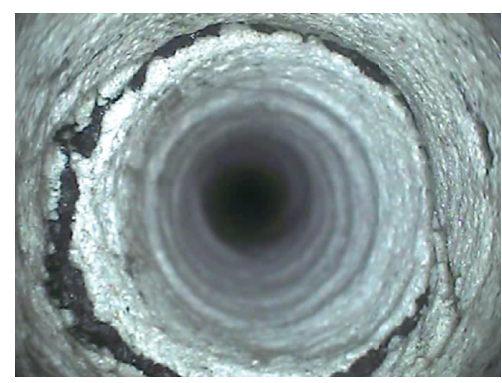

Depth $=12 \mathrm{~m}$

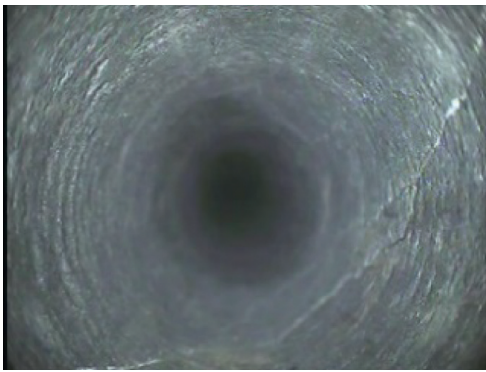

Depth $=6 \mathrm{~m}$

(a)

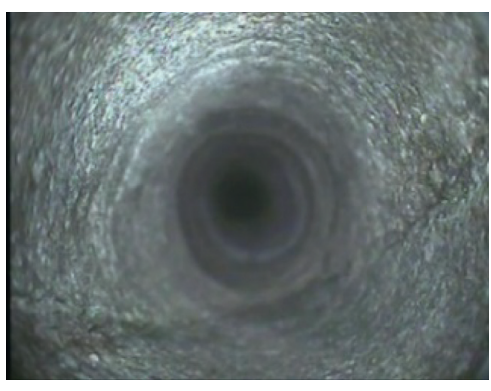

Depth $=6 \mathrm{~m}$

(b)

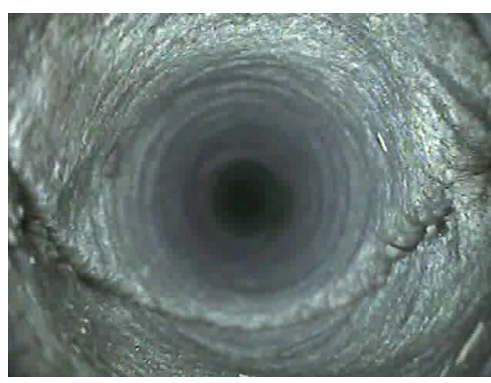

Depth $=6 \mathrm{~m}$

(c)

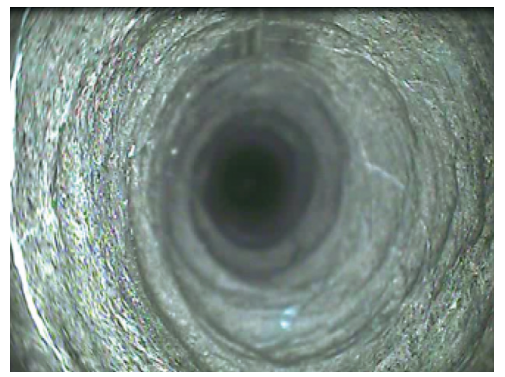

Depth $=1.2 \mathrm{~m}$

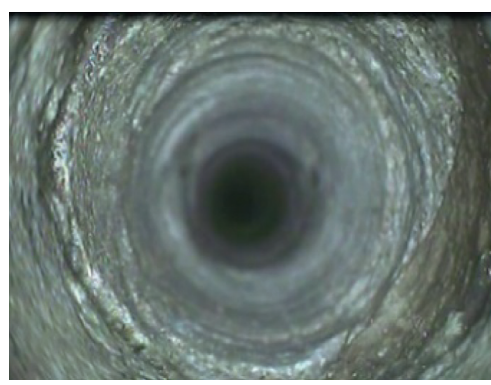

Depth $=1.2 \mathrm{~m}$

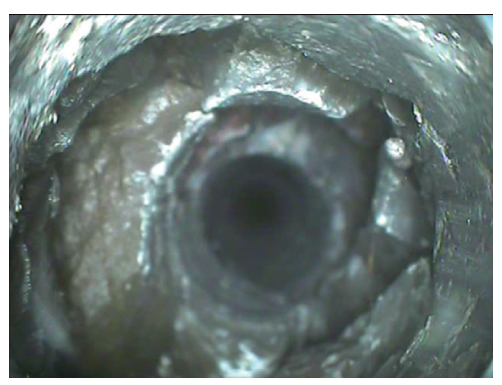

Depth $=1.2 \mathrm{~m}$

FIgURE 6: Fracture development in roof strata. (a) $50 \mathrm{~m}$ ahead of the face line. (b) $20 \mathrm{~m}$ ahead of face the line. (c) $10 \mathrm{~m}$ ahead of the face line.

located $12 \mathrm{~m}$ inside the borehole is intact, where a thin layer of coal seam is observed. At the depth of $6 \mathrm{~m}$ in the borehole, a close fracture intersects with the borehole wall, the dip angle of which reaches about $75^{\circ}$. In the vicinity of the borehole end, a series of horizontal fractures are formed. But, the fracture size is small. Such fractures are a result of 
gate extraction. As the stations move to a position $20 \mathrm{~m}$ inward the face line, small horizontal fractures initiate in the vicinity of the thin coal seam at the location $12 \mathrm{~m}$ inside the borehole. But the borehole wall still remains intact. As the location moves to $6 \mathrm{~m}$ inside the borehole, the close fracture starts to open. But, the aperture is small as shown in Figure 6(b). At the depth of $1.2 \mathrm{~m}$, the small horizontal fractures coalesce into a large fracture, leading to bedding separation of roof strata. When the station locates within the failure region of the seam, roof strata become strongly influenced by the longwall mining. As shown in Figure 6(c), bedding separation and small fractures appear in the vicinity of the thin coal seam. The aperture of the fracture located $6 \mathrm{~m}$ inside of the borehole reaches about $5 \mathrm{~mm}$. At the borehole end, the immediate roof is sheared into small fragments. Without bolt support, immediate roof within the region $1.2 \mathrm{~m}$ above the coal seam would cave under its own gravity.

\section{Numerical Modeling of the Mining- Induced Stress}

4.1. Model Configuration. The information on the stress distribution covered by the field measurements is limited. In order to reveal more information of the mining-induced stress, a large-scale numerical model is developed in this section, which is presented in Figure 7. The model is $1080 \mathrm{~m}$ in length and width, and its height is $130 \mathrm{~m}$. The bottom and four sides of the numerical model are fixed displacement boundaries. The top surface is set to be stress boundary through applying a compressive load of 22.5 MPa. This load is equal to the gravity of rock strata which are not included in the numerical model. The initial ground stress is assigned to the model in accordance to the field measurements. The major, intermediate, and minor principal directions are parallel with $z, y$, and $x$ axes, respectively. There are two longwall panels being included in the model, which are separated by a $100 \mathrm{~m}$ wide coal pillar. The longwall face, with the length of $350 \mathrm{~m}$, is installed at the face start line. There is an angle of $30^{\circ}$ existing between face advance and minor principal directions, which is consistent with the mining condition plotted in Figure 1. In the numerical model, panel 121303 is first mined, followed by panel 121304 . Thus, the influence of the gob left by the extraction of panel 121303 is taken into account. Note that the thick coal seam is extracted by $2 \mathrm{~m}$ per step. With face advancement, a monitoring line is installed in the coal seam, as shown in Figure 7.

In order to simulate mechanical behavior of the surrounding rock in a realistic way, the constitutive model developed by Wang et al. is assigned to the coal measure rocks included in the numerical model [35]. Rock mass properties, as listed in Table 2, are estimated from the intact rock properties (listed in Table 1) by using the geological strength index system proposed by Hoek and Brown [36]. In Table 2, parameters $m, n$, and $k$ are strain-softening indexes of the referred constitutive model, which are determined according to method proposed by Wang et al. [35]. In order to simulate the influence of roof rupture on stress distribution, the largest tensile stress of the main roof is tracked in the modeling process. If the largest tensile stress reaches the tensile strength of the main roof, namely, the zone fails in tension, both tensile strength and cohesive strength of this zone are set to be zero. In this way, the failure zone plays a similar role with real discontinuous fracture in cutting off the transfer path of mining-induced stress. Thus, fracturing behavior of the main roof can be simulated implicitly, and its influence on mining-induced stress is taken into account. With respect to caving materials in the gob area, double yield criterion is utilized to simulate the consolidation behavior $[37,38]$. The properties for gob materials are determined by comparing the predicted data with the empirical equation proposed by Salamon [18], which are listed in Table 3. Note that evolution of the cap pressure composed of the doubleyield model is controlled with the model proposed by Wang et al. [31]:

$$
p=a\left(\mathrm{e}^{b \varepsilon_{m}^{p s}}-1\right)+c \varepsilon_{m}^{p s},
$$

where $p$ is the cap pressure, $\varepsilon_{m}^{p s}$ is the volumetric plastic strain of caved materials, and $a, b$, and $c$ are the cap pressure model parameters.

4.2. Model Validation. Spatial distribution of the vertical stress in panel 121304 is extracted from the numerical model and displayed in Figure 8. It is obviously revealed that the vertical stress in the vicinity of the gob area is significantly increased due to the influence provided by the longwall mining. Two peak values appear on two sides of the face wall ahead of the longwall face. That is attributed to the roadways on two sides of the longwall panel. In the gob area, the vertical stress is drastically released because the load-bearing capacity of the caving materials is small. But, the caving materials are gradually compacted by roof strata movement with enlargement in the face advancement. Thus, vertical stress shows increasing trend with the growth in the distance between the longwall face and gob materials. As the longwall face advances $300 \mathrm{~m}$ from the face start line, the largest vertical stress increases to about $20 \mathrm{MPa}$ in the gob area, which means about $67 \%$ of the initial ground stress is recovered. Such distribution of the vertical stress is consistent with the field measurements illustrated in Figure 4. In order to conduct quantitative comparison, vertical stress along the monitoring line is extracted from Figure 8 and presented in Figure 4, which shows a similar evolution trend with the insitu data. The peak point locates about $13 \mathrm{~m}$ ahead of the longwall face and the influence range of the vertical stress reaches $150 \mathrm{~m}$. Such data from the numerical model agree well with the field measurements, indicating that the developed model is reliable.

4.3. The Evolution of the Principal Stress. The evolution of the major principal stress along the monitoring line with face advancement is plotted in Figure 9(a), which shows a similar trend with the vertical stress. Initial value of the major principal stress in the coal seam uninfluenced by the longwall mining is about $24 \mathrm{MPa}$, equal to the field measurement. The concentration and recovery phenomenon are 


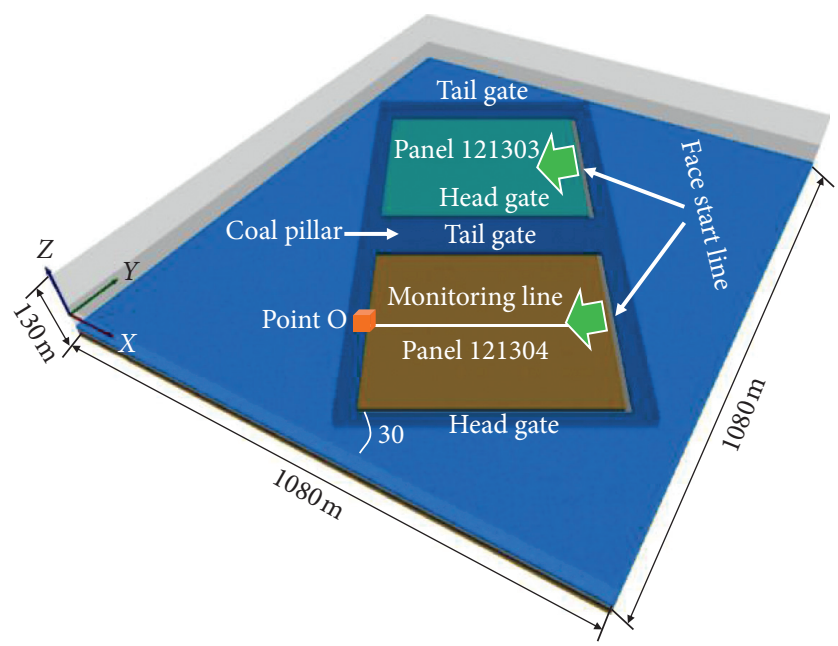

FIgURE 7: Numerical model including two longwall panels.

TABLE 2: Rock mass properties.

\begin{tabular}{lccccccc}
\hline Rock mass & $E(\mathrm{GPa})$ & $v$ & Cohesion $(\mathrm{MPa})$ & Friction $\left(^{\circ}\right)$ & Tensile strength $(\mathrm{MPa})$ & $m$ & $n$ \\
\hline Coal & 2.8 & 0.20 & 1.3 & 30 & 0.2 & 0.6 & 0.035 \\
Mudstone & 14.7 & 0.25 & 2.4 & 32 & 1.3 & 0.0021 & 0.56 \\
Siltstone & 17.5 & 0.25 & 5.0 & 33 & 320 \\
Sandstone & 21.2 & 0.16 & 10.0 & 38 & 2.0 & 0.0015 & 0.65 \\
\hline
\end{tabular}

TABle 3: Gob material properties.

\begin{tabular}{lcccccccc}
\hline Property & $\begin{array}{c}\text { Density } \\
\left(\mathrm{kg} / \mathrm{m}^{3}\right)\end{array}$ & $\begin{array}{c}\text { Bulk modulus } \\
(\mathrm{GPa})\end{array}$ & $\begin{array}{c}\text { Shear modulus } \\
(\mathrm{GPa})\end{array}$ & $\begin{array}{c}\text { Cohesion } \\
(\mathrm{MPa})\end{array}$ & $\begin{array}{c}\text { Friction } \\
\left({ }^{\circ}\right)\end{array}$ & $\begin{array}{c}\text { Tensile strength } \\
(\mathrm{MPa})\end{array}$ & $\begin{array}{c}a \\
(\mathrm{MPa})\end{array}$ & $\begin{array}{c}b \\
-\end{array}$ \\
\hline Value & 2000 & 1.2 & 0.6 & 0 & 30 & 0 & 60 & 15 \\
$(\mathrm{MPa})$
\end{tabular}

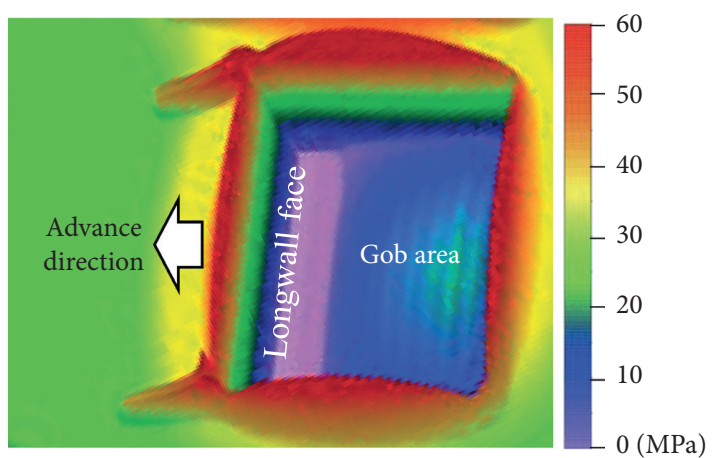

Figure 8: Spatial distribution of the vertical stress in panel 121304.

also experienced by the major principal stress in front and at the rear of the longwall face, respectively. The major principal stress recovers to about $18 \mathrm{MPa}$ in the gob when face advancement reaches $280 \mathrm{~m}$, reaching $75 \%$ of the initial value. Besides, main roof rupture leads to local decrease in the major principal stress. The region influenced by the longwall mining ahead of the longwall face reaches $152 \mathrm{~m}$, which is approximately equal to that influenced by the vertical stress.

The evolution of the minor principal stress on the monitoring line with face advancement is plotted in
Figure 9(b). The stress concentration and stress recovery phenomenon also occur to the minor principal stress under the influence of the longwall mining. In the unmined coal seam uninfluenced by the longwall mining, initial value of the minor principal stress is equal to $15 \mathrm{MPa}$, which is consistent with the field measurement. After being influenced by mining operations, the concentration degree of the minor principal stress is lower than that of the major principal stress. However, the influence provided by the main roof rupture on the minor principal stress is more obvious than that on the major principal stress. Besides, the recovery ratio of the minor principal stress in the gob area is smaller than that of the major principal stress. When the longwall face advances $280 \mathrm{~m}$ from face start line, the minor principal stress only recovers to about $6 \mathrm{MPa}$ in the gob area, accounting for $40 \%$ of the initial value. Local decrease is also experienced by the minor principal stress due to periodic rupture of the main roof. Regarding the minor principal stress, the region ahead of the longwall face influenced by the longwall mining increases to $172 \mathrm{~m}$.

Based on Figure 9, the variation in the peak stress concentration coefficient and peak point location with face advancement is moreover achieved and displayed in Figure 10. According to Figure 10(a), the concentration coefficients of the major and minor principal stresses present a similar increasing trend in the advancing process. The 


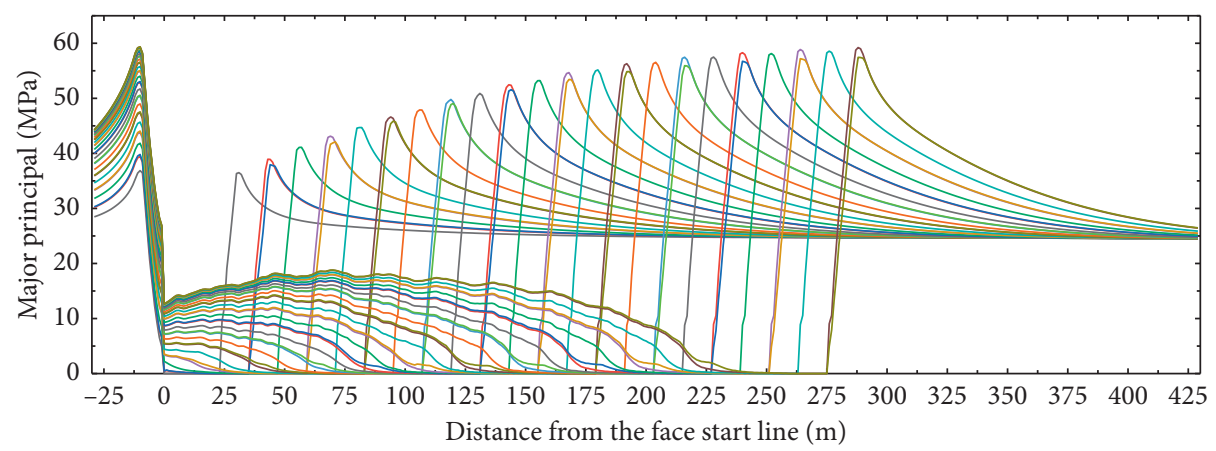

(a)

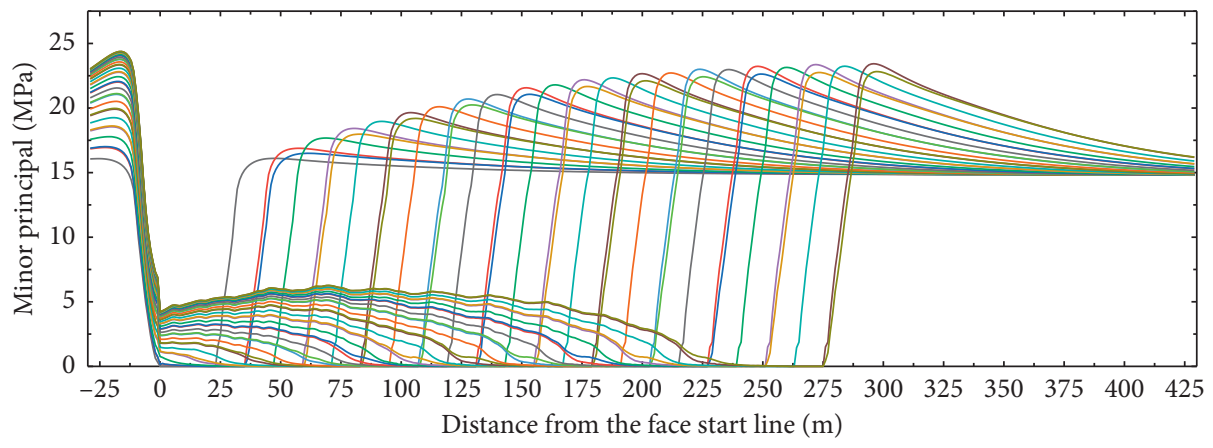

(b)

FIGURE 9: The evolution of the principal stress with face advancement. (a) Major principal stress. (b) Minor principal stress.

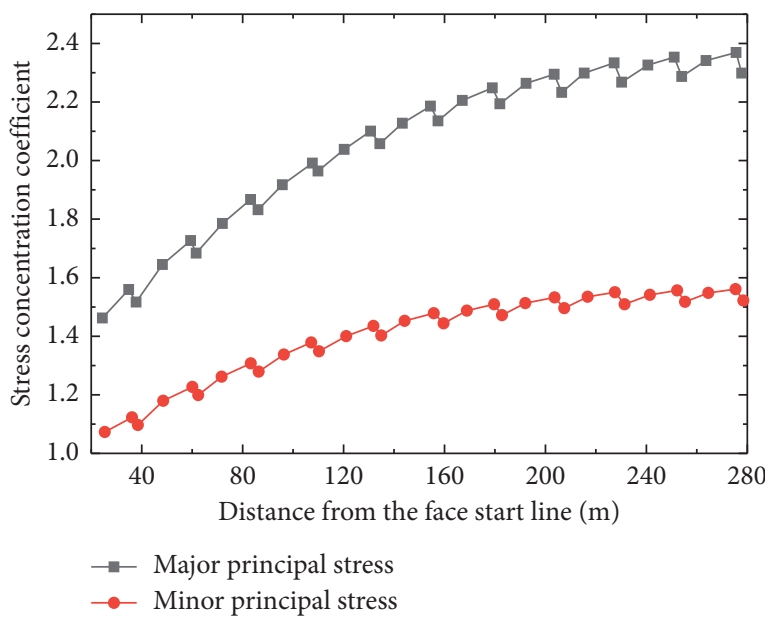

(a)

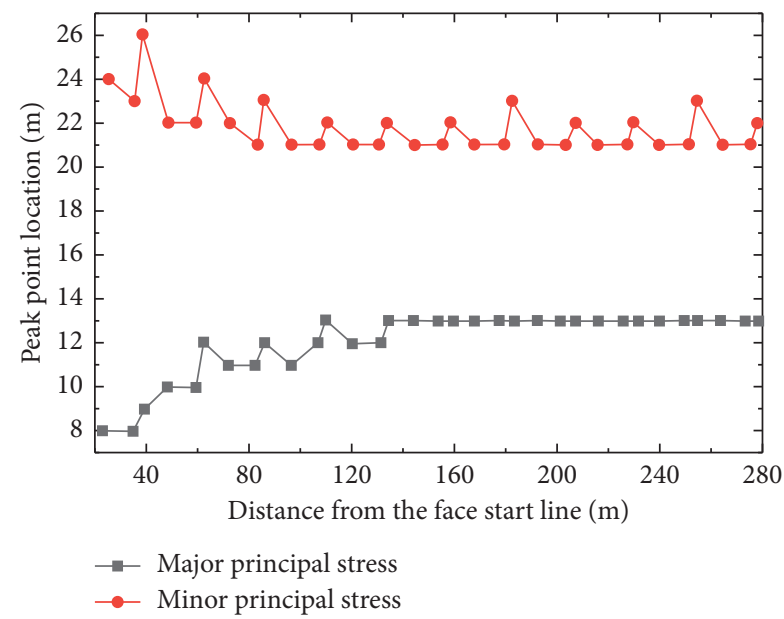

(b)

FIGURE 10: The variation in (a) stress concentration coefficient and (b) peak point location with face advancement.

increasing speed declines gradually with enlargement in the advancing distance. As the longwall face advances about $240 \mathrm{~m}$ from the face start line, the stress coefficient becomes insusceptible to the face advancement. Regarding the major and minor principal stresses, the stable coefficient magnitudes are 2.4 and 1.5 , respectively. The value corresponding to the major principal stress agrees well with that of the vertical stress in situ monitored. Periodic rupture of the main roof leads to local decease in the concentration coefficient.
The peak point location means that the distance from the peak point to the face line, as shown in Figure 10(b). Regarding the major and minor principal stresses, this distance shows an opposite evolution trend. With face advancement, the peak point of the major principal stress moves far away from the face line. In contrast, the peak point of the minor principal stress moves closer to the face line. As the longwall face advances about $140 \mathrm{~m}$ from the face start line, the peak point location becomes insusceptible to the face advancement. The peak point of the major principal stress locates about $13 \mathrm{~m}$ inward the face 
line, which is in accordance to the field measurement. The stable peak point of the minor principal stress stays $21 \mathrm{~m}$ ahead of the face line, significantly larger than that of the major principal stress. Besides, periodic rupture of the main roof leads to the enlargement in the distance between the face line and the peak point of the principal stress. However, with respect to the major principal stress, this distance becomes insusceptible to roof rupture as the face advancement increases to $140 \mathrm{~m}$.

4.4. Principal Stress Rotation. In order to investigate the rotation process experienced by the principal stress in the coal seam ahead of the face line, the stress data on the monitoring line are extracted from the numerical model. The principal stress, the stress in the initial principal direction, namely, vertical stress $\left(\sigma_{\mathrm{v}}\right)$, and the stress in $x$-axial direction $\left(\sigma_{x}\right)$, and their differences are presented in Figures 11(a) and 11(b). The principal direction is presented in the stereonet in Figures 11(c) and 11(d). Note that the lower hemisphere projection method is utilized to create the stereonet in this study. The $y$-axial and $x$-axial directions in the numerical model orientate to $0^{\circ}$ and $90^{\circ}$ on the stereonet. That means that the longwall face advances from $60^{\circ}$ to $240^{\circ}$ on the stereonet. According to Figures 11(a) and 11(b), the coal seam is initially uninfluenced by the longwall mining. Thus, the major and minor principal stresses stay in vertical and $x$-axial directions, respectively, at point O. As shown in Figure 11(a), from point $\mathrm{O}$ to point $\mathrm{A}$, the difference between the major principal and vertical stresses shows an increasing trend. It is easy to understand that the increase in the difference between the principal stress and the vertical stress implies the deviation of the principal stress from its initial direction. Thus, the major principal stress gradually deviates from the vertical direction and tilts toward the gob in this stage. At point $\mathrm{A}$, the dip angle of the major principal stress decreases to $75^{\circ}$. After that, the stress difference starts to decrease until point $B$ is approached. In this process, the major principal stress rotates reversely and nearly goes back to the vertical direction at point B. From point $\mathrm{B}$ to point $\mathrm{C}$, the stress difference increases again, which means an increase in the rotation angle of the major principal stress. But, the major principal stress rotates toward the face advance direction in this stage. At point $C$, the angle between the major principal stress and face advance directions decreases to $83^{\circ}$. Then, the major principal stress rotates back toward the vertical stress once again. At point $D$, the difference between the major principal and vertical stresses vanishes. As a result, point $\mathrm{D}$ and point $\mathrm{O}$ coincide on the stereonet. From point D to the face line (point E), the stress difference presents an increasing trend and the major principal stress tilts toward the gob area again. At point E, dip angle of the major principal stress decreases to $70^{\circ}$. Rotation process of the major principal stress nearly remains in the vertical plane parallel with the face advance direction.

Regarding the minor principal stress in Figures 11(c) and 11(d), its difference with $x$-axial stress also shows an increasing trend from point $\mathrm{O}$ to point $\mathrm{J}$. In this process, the minor principal stress rotates toward the vertical direction in the vertical plane parallel with the $x$-axial direction. Dip angle of the minor principal stress increases to $10^{\circ}$ at point J. The increasing rate of the stress difference rises abruptly from point $\mathrm{J}$ to point $\mathrm{K}$ and then to point $\mathrm{F}$. In the referred process, the minor principal stress deviates from the vertical plane parallel with $x$-axial direction, and it rotates gradually toward the vertical plane parallel with the face advance direction. From point $\mathrm{J}$ to point $\mathrm{K}$, rotation angle experienced by the minor principal stress in the horizontal plane reaches $20^{\circ}$. However, the dip angle of the minor principal stress decreases to $0^{\circ}$. From point $\mathrm{K}$ to point $\mathrm{F}$, the angle between the minor principal and $x$-axial directions and the dip angle of the minor principal stress show an increasing trend consistently. Within the region from point $\mathrm{F}$ to the face line (point $\mathrm{N}$ ), the difference between the minor principal and $x$-axial stresses drops quickly. From point $\mathrm{F}$ to point $\mathrm{M}$, the angle between the minor principal and $x$-axial directions is enlarged while the dip angle of the minor principal stress decreases to $0^{\circ}$ again. At point $M$, the minor principal stress rotates into the vertical plane parallel with the face advance direction. After that, rotation process of the minor principal stress remains in this plane. From point $M$ to point $\mathrm{N}$, the dip angle of the minor principal stress increases to $20^{\circ}$ at the same speed with the major principal stress.

In addition to the principal stress in the coal seam, the rotation phenomenon is also experienced by the principal stress in roof strata. As shown in Figure 12, the principal stress orientation along three lines parallel with the monitoring line are presented, which are $15 \mathrm{~m}$ (line 1), $60 \mathrm{~m}$ (line 2 ), and $100 \mathrm{~m}$ (line 3) above the coal seam in roof strata, respectively. In comparison with the principal stress in the coal seam, rotation angle of the principal stress in higher overburden strata is greatly enlarged. That means the principal stress orientation in roof strata is more sensitive to the longwall mining. Thus, the major and minor principal stresses deviate from vertical and $x$-axial directions at point $\mathrm{O}$ far away from the face line. With a decrease in the distance from the face line, the major principal stress tilts to the gob area in the vertical plane, parallel with $45^{\circ}-225^{\circ}$ direction, deviating at an angle of $15^{\circ}$ from the face advance direction due to the influence of the gob left by extraction of panel 121303. At the face line, the rotation angle experienced by the major principal stress on line 1 is relatively larger than that on lines 2 and 3 . The rotation traces of the major principal stress along three lines are similar except for local differences. Regarding the minor principal stress, it rotates gradually from horizontal to vertical direction. At the face line, the dip angle of the minor principal stress on three lines increases to about $45^{\circ}$, equal to the rotation angle of the major principal stress. Though the minor principal stress rotates toward the vertical plane, parallel with $45^{\circ}-225^{\circ}$ direction, consistently in the horizontal plane, rotation angle experienced by the minor principal stress along three lines varies a lot, leading to different rotation traces on the stereonet. Rotation angle experienced by the minor principal stress on line 1 in horizontal plane is much larger than that experienced by the minor principal stress on line 2 while such rotation angle of the minor principal stress on line 3 becomes negligible. The difference in the rotation trace of the minor principal stress on three lines is attributed to vertical distances from the coal seam. The larger distance from the coal seam leads to the weaker influence of the longwall 


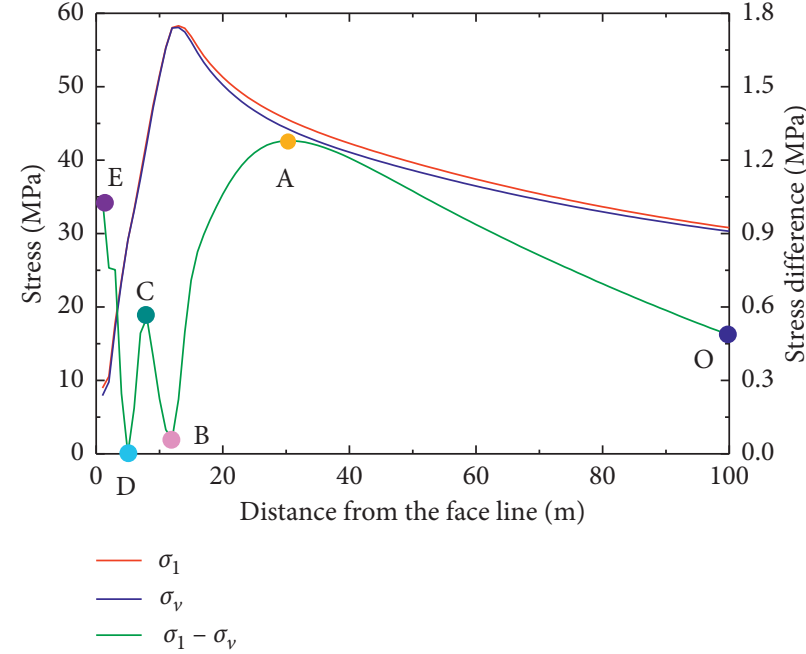

(a)

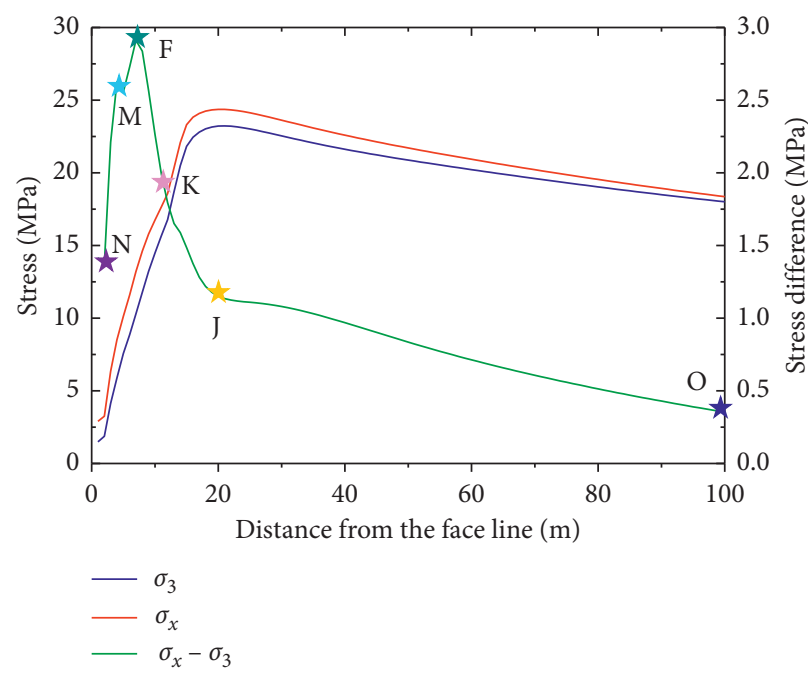

(c)

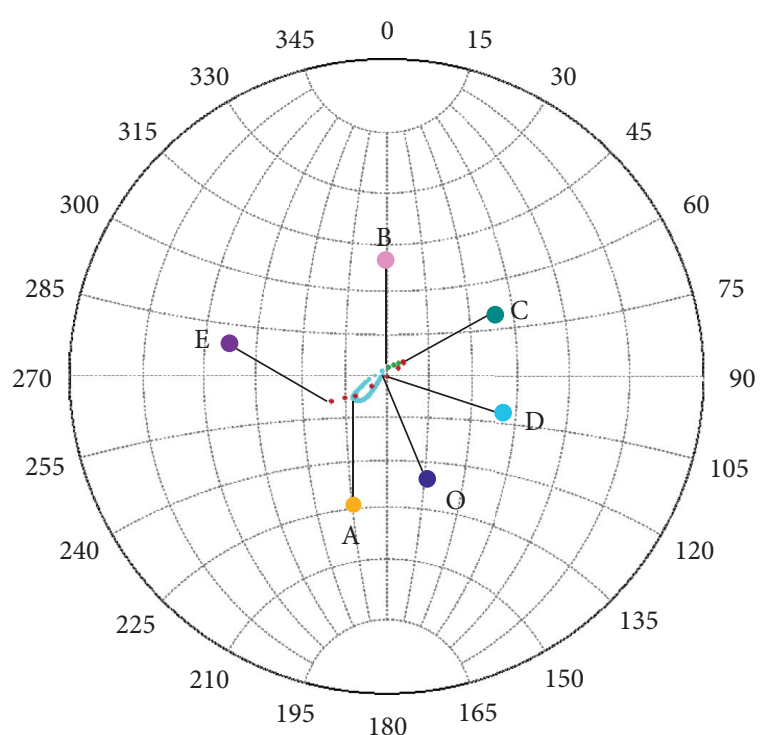

(b)

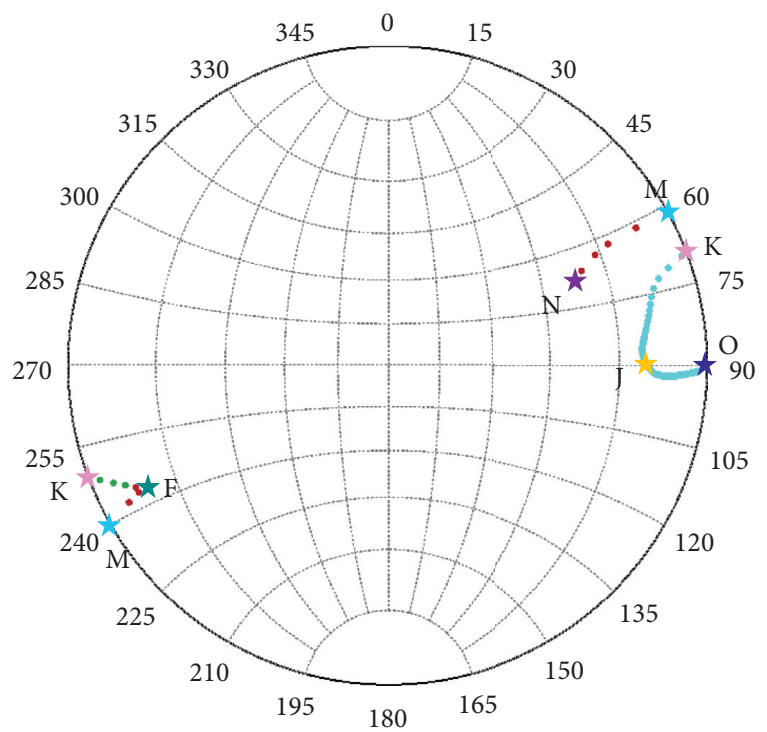

(d)

Figure 11: Stress rotation along the monitoring line. (a) Difference between the major principal and vertical stresses. (b) Rotation trace of the major principal stress. (c) Difference between the minor principal and $x$-axial stresses. (d) Rotation trace of the minor principal stress.

mining. As a result, rotation angle of the minor principal stress in the horizontal plane shows a decreasing trend from line 1 to line 3 . Besides, in the vertical direction, the rotation angle experienced by the minor principal stress on line 1 is relatively larger than that on lines 2 and 3 .

\section{Influence of Stress Rotation on Roof Structure}

In the longwall mining, mining-induced fractures tend to propagate in the direction perpendicular to the minor principal stress direction, which means the bending rupture plane is closely related to rotation trace of the minor principal stress. Besides, the orientation of the fracture formed by the rupture of the main roof provides great influence on roof structure stability. According to voussoir beam theory proposed by Qian [39], broken blocks of the main roof form a balance structure above the longwall face, which is defined as the voussoir beam structure (Figure 13). The broken blocks are composed of the structure contact at points $\mathrm{A}, \mathrm{B}$, and $\mathrm{C}$, and a temporal balance state is achieved. The structure greatly weakens the roof load applied on the hydraulic support in the longwall face. According to the voussoir beam theory, the structure remains stability when

$$
\frac{R}{T} \leq \tan (\varphi+\theta)
$$

where $\mathrm{R}$ and $\mathrm{T}$ are shear and normal forces at the contact point on the fracture plane, $\theta$ is the angle between the fracture plane and the vertical direction. 


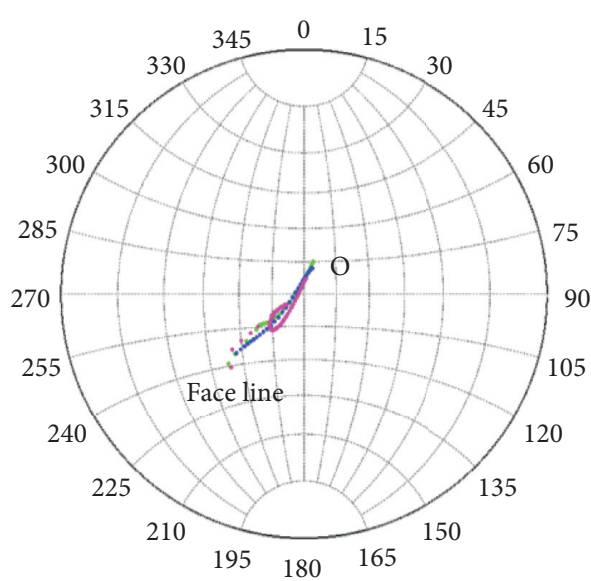

Line 1
Line 2
Line 3

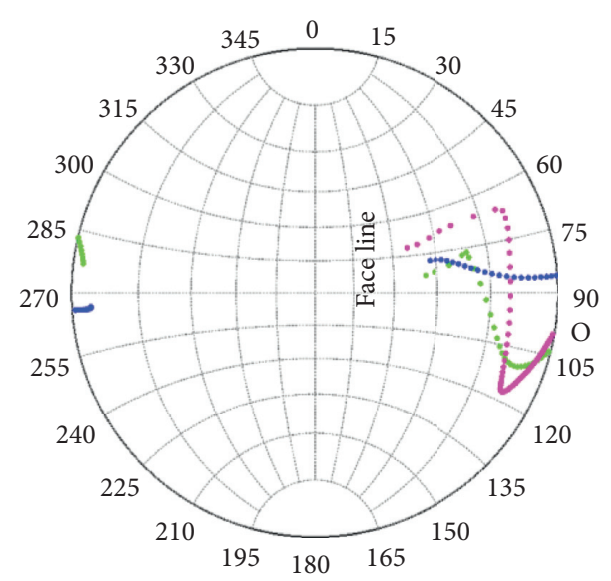

Line 1

Line 2

Line 3

Figure 12: Principal stress rotation in roof strata. (a) Major principal stress. (b) Minor principal stress.

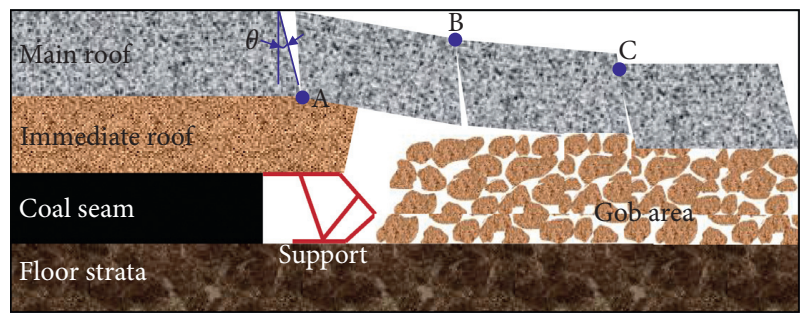

FIGURE 13: The voussoir beam structure.

If the fracture plane tilts toward the face advance direction, as shown in Figure 13, the value of $\theta$ is positive and the stability of the voussoir beam structure is greatly improved. However, if the fracture plane tilts toward the gob area, the value of $\theta$ is negative, indicating a bad roof structure condition. In both scenarios, the stability of the roof structure is closely related to the angle $\theta$. In fact, angle $\theta$ is equal to the final dip angle of the minor principal stress. Thus, if the rotation trace of the principal stress can be determined, the roof structure stability can be evaluated. Though the rotation trace of the minor principal stress is more complex than that of the major principal stress, it is also influenced by face advance direction. For the minor principal stress in roof strata, its rotation trace is also related to the vertical distance above the coal seam. Based on such an understanding, fracture orientation in the main roof can be determined. Moreover, the stability of the voussoir beam structure above the longwall face can be evaluated to guarantee the stability of the hydraulic support.

\section{Conclusions}

With an increase in the cover depth of the longwall mining, the difficulty in the surrounding rock control is greatly improved. The distribution of mining-induced stress is important to the surrounding rock stability. Thus, in the present study, stress analysis is carried out in a longwall panel with a face length of $350 \mathrm{~m}$ and a cover depth more than $1000 \mathrm{~m}$. Based on the field measurements and numerical modelling results, the following conclusions are drawn:

(1) Borehole stress monitoring indicates that the vertical stress shows an increasing trend at about $150 \mathrm{~m}$ ahead of the longwall face. The peak point is reached at the location 10 to $13 \mathrm{~m}$ inward the face line. After that, the coal seam fails and the vertical stress shows a decreasing trend. At the face line, vertical stress drops to 2.5 to $3.5 \mathrm{MPa}$. Multipoint displacement meter-based roof subsidence measurement reveals that immediate roof and main roof start to subside at about $150 \mathrm{~m}$ and $140 \mathrm{~m}$ ahead of the longwall face, respectively. Borehole camera detection shows that roof fracture development increases rapidly within the failure region of the coal seam.

(2) The modelling results show that the magnitude and influence scope of the principal stress show a rising trend with the enlargement in face advancement. They become stable when the advancement reaches $240 \mathrm{~m}$. The stable concentration coefficients of the major and minor principal stresses are 2.4 and 1.5, respectively. Corresponding influence scopes are 152 and $172 \mathrm{~m}$ ahead of the face line. The distances between the face line and peak points of the major and minor principal stresses initially show increasing and decreasing trends and then, they become stable with the advancement of $140 \mathrm{~m}$. The stable values are 13 and $21 \mathrm{~m}$, respectively.

(3) Longwall mining results in stress rotation, which influences the stability of the roof voussoir beam 
structure. In the coal seam, the major principal stress rotates from vertical to horizontal direction. The maximum rotation angle reaches $20^{\circ}$ and the rotation trace remains in the vertical plane $(\beta)$ parallel with the face advance direction. The minor principal stress first rotates into plane $\beta$ and then it rotates consistently with the major principal stress. Its rotation angle in the horizontal plane is equal to the angle between face advance and initial minor principal directions. Rotation angle of the principal stress in roof strata is greatly increased and its rotation trace is influenced by the longwall mining, adjacent gob area, and the distance above the coal seam.

\section{Data Availability}

The data used to support main conclusions of this study are included within the paper. The processed data are available from the corresponding author upon request.

\section{Conflicts of Interest}

The authors declare that they have no conflicts of interest.

\section{Acknowledgments}

This study was sponsored by the National Key R\&D Program of China (Grant No. 2017YFC0603002) and Key Laboratory of Mining Disaster Prevention and Control (Grant No. MDPC201906). It was also supported by the Fundamental Research Funds for the Central Universities. The authors are grateful for their support.

\section{References}

[1] H. Xie, H. Zhou, D. Xue, H. Wang, R. Zhang, and F. Gao, "Research and consideration on deep coal mining and critical mining depth," Journal of China Coal Society, vol. 37, no. 4, pp. 535-542, 2012.

[2] H. Xie, "Research review of the state key research development program of China: deep rock mechanics and mining theory," Journal of China Coal Society, vol. 44, no. 5, pp. 1283-1305, 2019.

[3] Q. Wang, B. Jiang, R. Pan et al., "Failure mechanism of surrounding rock with high stress and confined concrete support system," International Journal of Rock Mechanics and Mining Sciences, vol. 102, pp. 89-100, 2018.

[4] H. Kang, H. Lv, F. Gao, X. Meng, and Y. Feng, "Understanding mechanisms of destressing mining-induced stresses using hydraulic fracturing," International Journal of Coal Geology, vol. 196, pp. 19-28, 2018.

[5] P. Konicek, K. Soucek, L. Stas, and R. Singh, "Long-hole destress blasting for rockburst control during deep underground coal mining," International Journal of Rock Mechanics and Mining Sciences, vol. 61, pp. 141-153, 2013.

[6] J. Wang, S. Yang, B. Yang et al., "Roof sub-regional fracturing and support resistance distribution in deep longwall face with ultra-large length," Journal of China Coal Society, vol. 44, no. 1, pp. 54-63, 2019.

[7] J. Xie, J. Xu, and F. Wang, "Mining-induced stress distribution of the working face in a kilometer-deep coal mine-a case study in Tangshan coal mine," Journal of Geophysics and Engineering, vol. 15, no. 5, pp. 2060-2070, 2018.

[8] J.-c. Chang, "Distribution laws of abutment pressure around fully mechanized top-coal caving face by in-situ measurement," Journal of Coal Science and Engineering (China), vol. 17, no. 1, pp. 1-5, 2011.

[9] D. Song, E. Wang, X. He et al., "Use of electromagnetic radiation from fractures for mining-induced stress field assessment," Journal of Geophysics and Engineering, vol. 15, no. 4, pp. 1093-1103, 2018.

[10] A. K. Singh, R. Singh, J. Maiti, R. Kumar, and P. K. Mandal, "Assessment of mining induced stress development over coal pillars during depillaring," International Journal of Rock Mechanics and Mining Sciences, vol. 48, no. 5, pp. 805-818, 2011.

[11] H. Guo, L. Yuan, B. Shen, Q. Qu, and J. Xue, "Mining-induced strata stress changes, fractures and gas flow dynamics in multi-seam longwall mining," International Journal of Rock Mechanics and Mining Sciences, vol. 54, pp. 129-139, 2012.

[12] P. Kaiser, S. Yazici, and S. Maloney, "Mining-induced stress change and consequences of stress path on excavation stability-a case study," International Journal of Rock Mechanics and Mining Sciences, vol. 38, pp. 167-180, 2011.

[13] P. Konicek and P. Waclawik, "Stress changes and seismicity monitoring of hard coal longwall mining in high rockburst risk areas," Tunnelling and Underground Space Technology, vol. 81, pp. 237-251, 2018.

[14] J. Liu, Y. Li, and S. Xu, "Relationship between microseismic activities and mining parameters during deep mining process," Journal of Applied Geophysics, vol. 159, pp. 814-823, 2018.

[15] S. Wang and Q. Huang, "Study on roof weighting of $400 \mathrm{~m}$ fully-mechanized mining face in shallow coal seam," International Journal of Coal Science and Technology, vol. 46, no. S1, pp. 75-80, 2018.

[16] B. Lund and M. D. Zoback, "Orientation and magnitude of in situ stress to $6.5 \mathrm{~km}$ depth in the baltic shield," International Journal of Rock Mechanics and Mining Sciences, vol. 36, no. 2, pp. 169-190, 1999.

[17] A. G. Corkum, B. Damjanac, and T. Lam, "Variation of horizontal in situ stress with depth for long-term performance evaluation of the deep geological repository project access shaft," International Journal of Rock Mechanics and Mining Sciences, vol. 107, pp. 75-85, 2018.

[18] M. Salamon, "Elastic analysis of displacements and stress induced by the mining of seam or reef deposits, part II," Journal of the Southern African Institute of Mining and Metallurgy, vol. 64, no. 6, pp. 197-218, 1964.

[19] B. Whittaker and R. Singh, "Design and stability of pillars in longwall mining," Mining Engineering, vol. 139, pp. 59-70, 1979.

[20] A. H. Wilson, "The stability of underground workings in the soft rocks of the Coal Measures," International Journal of Mining Engineering, vol. 1, no. 2, pp. 91-187, 1983.

[21] D. Xue, J. Wang, Y. Zhao, and H. Zhou, "Quantitative determination of mining-induced discontinuous stress drop in coal," International Journal of Rock Mechanics and Mining Sciences, vol. 111, pp. 1-11, 2018.

[22] M. Shabanimashcool and C. C. Li, "Numerical modelling of longwall mining and stability analysis of the gates in a coal mine," International Journal of Rock Mechanics and Mining Sciences, vol. 51, pp. 24-34, 2012.

[23] M. Shabanimashcool and C. C. Li, "A numerical study of stress changes in barrier pillars and a border area in a longwall 
coal mine," International Journal of Coal Geology, vol. 106, pp. 39-47, 2013.

[24] Y. Ju, Y. Wang, C. Su, D. Zhang, and Z. Ren, "Numerical analysis of the dynamic evolution of mining-induced stresses and fractures in multilayered rock strata using continuumbased discrete element methods," International Journal of Rock Mechanics and Mining Sciences, vol. 113, pp. 191-210, 2019.

[25] H. Basarir, I. Ferid Oge, and O. Aydin, "Prediction of the stresses around main and tail gates during top coal caving by 3D numerical analysis," International Journal of Rock Mechanics and Mining Sciences, vol. 76, pp. 88-97, 2015.

[26] H. G. Ji, H. S. Ma, J. A. Wang, Y. H. Zhang, and H. Cao, "Mining disturbance effect and mining arrangements analysis of near-fault mining in high tectonic stress region," Safety Science, vol. 50, no. 4, pp. 649-654, 2012.

[27] E. Eberhardt, "Numerical modelling of three-dimension stress rotation ahead of an advancing tunnel face," International Journal of Rock Mechanics and Mining Sciences, vol. 38, no. 4, pp. 499-518, 2001.

[28] M. S. Diederichs, P. K. Kaiser, and E. Eberhardt, "Damage initiation and propagation in hard rock during tunnelling and the influence of near-face stress rotation," International Journal of Rock Mechanics and Mining Sciences, vol. 41, no. 5, pp. 785-812, 2004.

[29] J. Wang and Z. Wang, "Propagating mechanism of top-coal fracture in longwall top-coal caving mining," Journal of China Coal Society, vol. 43, no. 9, pp. 2400-2413, 2018.

[30] J. Wang, Z. Wang, and Y. Li, "Longwall top coal caving mechanisms in the fractured thick coal seam," International Journal of Geomechanics, vol. 20, no. 8, 2020.

[31] J. C. Wang, Z. H. Wang, and S. L. Yang, "Stress analysis of longwall top-coal caving face adjacent to the gob," International Journal of Mining, Reclamation and Environment, vol. 34, no. 7, pp. 476-497, 2020.

[32] H. Kang, G. Wang, P. Jiang et al., "Conception for strata control and intelligent mining technology in deep coal mines with depth more than 1000 m," Journal of China Coal Society, vol. 43, no. 7, pp. 1789-1800, 2018.

[33] S. R. Islavath, D. Deb, and H. Kumar, "Numerical analysis of a longwall mining cycle and development of a composite longwall index," International Journal of Rock Mechanics and Mining Sciences, vol. 89, pp. 43-54, 2016.

[34] H. Yavuz, "An estimation method for cover pressure re-establishment distance and pressure distribution in the goaf of longwall coal mines," International Journal of Rock Mechanics and Mining Sciences, vol. 41, no. 2, pp. 193-205, 2004.

[35] J. Wang, Z. Wang, and S. Yang, "A coupled macro- and mesomechanical model for heterogeneous coal," International Journal of Rock Mechanics and Mining Sciences, vol. 94, pp. 64-81, 2017.

[36] E. Hoek and E. T. Brown, "Practical estimates of rock mass strength," International Journal of Rock Mechanics and Mining Sciences, vol. 34, no. 8, pp. 1165-1186, 1997.

[37] G. C. Zhang, Z. J. Wen, S. J. Liang et al., "Ground response of a gob-side entry in a longwall panel extracting $17 \mathrm{~m}$-thick coal seam: a case study," Rock Mechanics and Rock Engineering, vol. 53, no. 2, pp. 497-516, 2020.

[38] L. Jiang, P. Zhang, L. Chen et al., "Numerical approach for goaf-side entry layout and yield pillar design in fractured ground conditions," Rock Mechanics and Rock Engineering, vol. 50, no. 11, pp. 3049-3071, 2017.
[39] M. G. Qian, Strata Control and Sustainable Coal Mining, China University of Mining and Technology Press, Xuzhou, China, 2011. 